\title{
Lasting Effects of Pediatric Traumatic Brain Injury
}

\author{
Christopher C. Giza, M.D \\ Divisions of Neurosurgery and Pediatric Neurology \\ David Geffen School of Medicine at UCLA, Los Angeles, CA
}

\begin{abstract}
The number one cause of death and disability in children and teenagers is traumatic brain injury. Despite this fact, this clinical scourge receives limited research investigation. Given the remarkable recovery often seen after focal childhood brain injuries (infarction, hemorrhage, surgical excision), there is a common misconception that the younger brain is always more resilient. However, increasing evidence suggests that this assumption is incorrect. First, TBI represents a diffuse type of brain injury, and both clinical and laboratory studies suggest that the immature brain is less capable of recovering from such damage. Second, there appear to be developmental windows wherein diffuse injury can result in lost potential; at time this loss may only be detectable at a later stage of brain maturation. In addition to understanding these complex concepts of TBI sustained during development, consideration will also be given to relating these concepts to chronic sequelae of pediatric TBI, including cell death and regional brain atrophy, cognitive and behavioral deficits, and altered trajectories of brain maturation.
\end{abstract}

Keywords: child, development, head injury, immature, plasticity

\section{INTRODUCTION}

Accidents involving head injury are a major cause of pediatric death and disability worldwide. Nonetheless, most of our understanding and most of our clinical management of pediatric traumatic brain injury (TBI) is extrapolated from adults. Children are not just "little adults", and there are many important distinctions between the developing and mature brain, particularly with regards to normal function, pathophysiological response to injury, recovery and plasticity. This review will articulate some of these fundamental differences, as well as discuss both basic mechanisms and clinical correlates of developmental TBI.

\section{DISTINCTIONS OF INJURY IN THE DEVEOPING BRAIN}

The developing brain is a unique physiological substrate and is generally believed to be more resilient to injury than the adult brain. However, in recent years, this dogma has been increasingly challenged. It is more correct to state that the immature brain does have some inherent advantages with regards to injury response and recovery; however, it also has clear vulnerabilities that are to some extent based upon the underlying developmental processes ongoing at the time of injury.

One fundamental distinction of pediatric TBI is purely physical. The pediatric skull is thinner and more pliable

Address for correspondence: Room 18-235 NPI, Mail code 703919 Division of Neurosurgery David Geffen School of Medicine at UCLA Los Angeles, CA 90095

Phone: 1-310-206-3480

Fax: 1-310-794-2147 Email: cgiza@mednet.ucla.edu than the adult. Particularly in infants, the flexibility of the sutures and the presence of an open fontanelle may result in significant alterations in the force transmitted to the brain by a traumatic injury, as well as differences in the response to increased intracranial pressure resulting from posttraumatic cerebral edema. In the pediatric age range, the size of the head relative to the body is also disproportionately large when compared with adults. At the same time, the neck musculature is often less developed and the cervical ligaments and joints are more flexible. These factors are important considerations when evaluating a child with head injury, particularly by a medical professional whose primary experience is with adults.

Mechanisms of injury also vary based on age. Toddlers are significantly more likely to sustain TBI as a result of a fall, while older children and teenagers are more likely to experience TBI due to vehicular accidents and sports. Assaults also increasingly contribute to TBI in adolescents and young adults. Assaults (nonaccidental trauma) also occurs in infants, and, while it may be difficult to initially diagnose, is of critical important because of the severity of these injuries and the long term implications for impaired development.

In addition to the above factors, it is important to understand the normal physiology of the developing brain. Brain water content is higher, resulting in reduced brain compliance. Cerebral blood flow (CBF) shows age-specific differences; in general, higher $\mathrm{CBF}$ is seen during development and declines with maturation ${ }^{1,2}$. The maturing brain goes through a phase of maximal synaptogenesis, followed by pruning and refinement of circuitry, usually in an experience-dependent fashion. This period of maximal 
connectivity is associated with increased levels of glucose metabolism $^{3}$, higher levels of neurotrophic factors ${ }^{4}$ and elevated excitatory amino acid receptor binding and expression ${ }^{5,6}$. These age-dependent parameters may confer an increased excitability to the immature brain, factors that may facilitate enhanced plasticity and recovery from injury. However, there is also a potential downside, namely, that increased excitability also increases the risk for early posttraumatic seizures ${ }^{7}$ and excitotoxicity ${ }^{8}$. Furthermore, since the young brain relies on some level of activity for normal development, post-traumatic depression of neural activity, either physiologically or pharmacologically enhanced (through the use of excitotoxicity inhibitors), may actually be detrimental, resulting in lost developmental potential $1^{9,10}$ and even in substantially increased levels of apoptosis ${ }^{11,12}$.

\section{ACUTE PHYSIOLOGICAL ETECTS OF PEDIATRIC/DEVELOPMENTAL TBI}

The pathophysiological response of the developing brain, while resembling that of the mature brain in some ways, clearly has its own distinct signature. From extensive experimental modeling of TBI in the lab, and corroboration from translational studies in ICU patients, it is known that TBI induces a neurometabolic cascade of cellular and physiological effects (for more detailed review, see Madikians and Giza in this issue). This cascade starts with an indiscriminate release of glutamate and efflux of potassium into the extracellular space ${ }^{13,14}$. To restore homeostasis, ionic pumps acutely work overtime and reduce cellular ATP. This, in turn, increases cellular glucose uptake in an attempt to increase energy production. This brief hyperglycolysis is followed by a more prolonged period of reduced glucose uptake. In adult experimental animals, this period of diminished metabolism may last up to 7-10 days and has been correlated with the duration of postTBI cognitive deficits ${ }^{15}$. In younger animals, the same general metabolic profile is seen; however, the time course appears to be shorter ${ }^{16}$ and the behavioral manifestations more subtle $\mathrm{e}^{17,18}$.

Accompanying the post-TBI glutamate release is an accumulation of intracellular calcium. This may result in mitochondrial dysfunction, protease activation, and eventually, cell death. Interestingly, the pattern of postTBI calcium accumulation appears to differ based on ageat-injury. The adult pattern of post-TBI calcium influx shows dense focal accumulation near the site of injury, at the gray-white junction location of an evolving contusion. In the younger animals, there is a more diffuse pattern of calcium influx, without the focal component. Adults also show a delayed calcium accumulation in the ipsilateral thalamus that is associated with secondary cell death. This pattern was not seen after a comparable developmental $\mathrm{TBI}^{19}$.

\section{POST-TRAUMATIC CELL DEATH}

Early cell death after TBI in developing animals is variable and appears to depend upon both injury model and injury severity. After mild and moderate lateral fluid percussion injury (FPI) in the postnatal day 17 (P17) rat, no difference was detected on gross morphology or parietal cortex cell counts $^{20}$. Similar results were reported using stereological counting of cortical and hippocampal CA3 neurons 2 weeks after FPI in the P19 rat pup ${ }^{21}$. Using a closed-head weight drop injury at the same age, Adelson and colleagues noted edema, glial activation and damage to brainstem white matter tracts, but no significant neuronal death ${ }^{22}$. In comparison, adult lateral FPI has been well known to cause neuron loss, cortical thinning and ipsilateral ventricular enlargement, processes that may progress over months ${ }^{23}$. These studies suggest that, at least near the time of weaning, the developing rat brain is somewhat resistant to trauma-induced cell death. Interestingly, the developing (P21) mouse, when subjected to a controlled cortical impact (CCI) injury, shows a pattern of damage regionally similar to the adult, with cavitation of the ipsilateral cortex and loss of neurons in the hippocampal CA2/3 subfields ${ }^{24}$. These comparisons only further illustrate the importance of species, age, injury model and severity when interpreting studies of developmental TBI (for review, $\mathrm{see}^{25}$ ).

In even younger rats, there appears to be a significant difference in vulnerability to TBI. Using a similar closed head weight drop model as Adelson, but in P3-P10 rats, both excitotoxic (necrotic) and delayed apoptotic cell death have been reported ${ }^{11,12}$. Indeed, these investigators demonstrated that apoptotic cell death appears to play a larger role after neonatal TBI than in weanling or mature animals. When NMDAR antagonists were utilized to prevent early TBI-induced excitotoxicity, the acute cell death was mitigated, but a massive wave of subsequent apoptosis occurred ${ }^{11,12,26}$. This has been interpreted as an indication of the importance of excitatory neural activity in the developing brain, where excitatory transmission is necessary for synaptic strengthening and release of trophic factors. Furthermore, it suggests that the indiscriminate blockade of glutamatergic responses, while protective against excitotoxic insults, may be detrimental to the activity-dependent processes that facilitate recovery ${ }^{27}$.

It should be noted, however, that in P14-P30 rats, the same investigators found markedly reduced levels of TUNEL-staining as compared to the younger P3-P10 rats. This finding corroborates the studies described above that 
showed less neuronal death in the P17-19 rats $^{20-22}$, and may indicate that cellular dysfunction, rather than cell death, contributes more to the post-TBI neurological impairments seen in weanling rats.

More recently, volumetric MRI techniques have permitted quantitation of regional brain volumes in children who sustained moderate to severe TBI. Enlarged ventricles and brain atrophy have been reported after pediatric $\mathrm{TBI}^{28,29}$. The growth of the corpus callosum is impaired in the three years following severe pediatric $\mathrm{TBI}^{30}$. Specific regional quantification reveals loss of brain volume in both frontal and temporal lobes in children at least 1 year post$\mathrm{TBI}^{31}$. Furthermore, there was a strong correlation between frontotemporal brain volumes and pediatric-modified Glasgow Outcome Scale scores, indicating that these changes may have functional significance ${ }^{31}$.

Thus, experimental TBI in the immature brain can model mild TBI, with primarily cellular physiological dysfunction and little cell death. These injuries may more closely model mild or moderate clinical pediatric TBI, including concussion. Experimental TBI can also model severe pediatric TBI, with cell death and tissue loss. In the rat, apoptosis plays a disproportionate role in eventual postTBI cell death, but indiscriminate inhibitors of excitatory neurotransmission may also induce massive apoptosis, suggesting that age-specific neuroprotective strategies are necessary. In children, delayed loss of brain volume also seems to occur after severe TBI, and further studies will be necessary to determine the time course, mechanism and functional consequences of this tissue loss.

\section{CHRONIC COGNITIVE IMPAIRMENT}

The significance of TBI is manifest through sequelae such as cognitive and behavioral deficits, affecting functions such as memory and attention. These neurocognitive deficits may come about through two main mechanisms. First, loss of cells from the acute injury and subsequent apoptotic degeneration over time may underlie these behavioral problems. Second, a period of lost neural responsiveness during development may ultimately lead to aberrant brain maturation and a long-lasting cognitive impairment (see next section).

In experimental models of developmental TBI, transient behavioral deficits have been reported, often coinciding with periods of cellular or molecular dysfunction after the injury. However, demonstrating chronic deficits has been more elusive in the developing animal. Postnatal day 17-19 pups that sustained fluid percussion injury did not have demonstrable deficits on acquisition of the Morris water maze (MWM) task, even if the MWM training was delayed by 1 week or 1 month post-injury,10,17,18. Likewise, chronic cognitive deficits in the MWM were not seen using the closed head weight drop model, even when a secondary ischemic insult was added ${ }^{32}$. Only at an 'ultra-severe' level of injury were long-lasting MWM deficits noted ${ }^{32,33}$, up to 22 days post-TBI. Although milder developmental injuries did not appear to result in permanent behavioral sequelae, studies in adult rats have shown that an accumulation of mild injuries (individually without behavioral sequelae) can result in detectable impairment in MWM acquisition ${ }^{34}$.

Clinically, children also seem to recover from milder injuries with apparently little neurological or cognitive impairment. However, there is increasing evidence from sports injuries in adolescents and young adults, that repeated concussion can be associated with long-term neuropsychological dysfunction ${ }^{35-38}$. Furthermore, TBI at a particular stage of maturation may result in specific deficits in cognitive domains undergoing development at that stage $\mathrm{e}^{39-41}$. This suggests that underlying perturbations of developmental plasticity may also be relevant for recovery from pediatric TBI, and will be discussed in greater detail in the following section. Certainly, it is well known that moderate and severe pediatric TBI can result in profound intellectual and cognitive deficits, as well as changes in personality and behavior ${ }^{42-45}$.

\section{A TRAUMA-INDUCED DEVEIOPMENTAL DEGCT DIMINISHED NEURAL RESPONSIVENESS EARLY AFTER TBI}

Several acute molecular responses of the immature brain warrant mention here because of their potential to affect ongoing developmental plasticity and thus, result in lasting behavioral deficits. First, microarray expression analysis of TBI in developing animals reveals impairment of several classes of genes that may underlie normal plasticity, including extracellular adhesion molecules, metabolic enzymes, neurotransmitter receptors and cytoskeletal proteins ${ }^{46,47}$. Next, molecular markers of synaptic activity, such as synaptophysin and brain derived neurotrophic factor (BDNF), have been shown to have altered patterns of regional expression after traumatic injury to the immature brain $^{48,49}$. Lastly, the primary excitatory neurotransmitter receptor, the N-methyl-D-aspartate receptor (NMDAR), shows subunit specific reductions after developmental $\mathrm{TBI}^{50,51}$. These reductions can essentially delay the normal maturation of the NMDAR and result in a period of postTBI neural dysfunction that may be correlated with impaired cognition and reduced responsiveness to environmental stimulation.

Long-term potentiation (LTP) is an electrophysiological 
phenomenon that has been associated with learning and memory, and is in many cases, NMDAR-dependent. Following FPI in juvenile rats (P24-31), D'Ambrosio et al., reported impaired LTP generation, thus demonstrating impaired post-injury responsiveness in the developing brain $^{52}$. While impaired neural activation after TBI has also been shown in adult animals ${ }^{53,54}$, the long-term consequences may be magnified during development, if such reduced responsiveness occurs during a critical maturational period.

In adults, there is also evidence of reduced NMDAR function in the subacute period after TBI. Levels of NMDAR proteins and radioisotope calcium accumulation are reduced in a subunit-specific fashion after lateral $\mathrm{FPI}^{55}$. In post-TBI conditions, NMDAR binding is also reduced. In fact, by treating in the post-acute period with NMDA, cognitive deficits in adult rats were improved ${ }^{56}$.

Reduced activation of neural circuitry can occur due to intrinsic neuronal dysfunction, but may also be due to impaired connectivity. White matter lesions such as those seen in diffuse axonal injury are not uncommon following TBI, and have been specifically reported in developing animals ${ }^{57}$ and in pediatric patients after $\mathrm{TBI}^{58,59}$. Furthermore, the burden of these lesions has been associated with increasing cognitive and behavioral impairment in children ${ }^{59}$, suggesting that disconnection may also play a significant role in the loss of developmental potential seen after early TBI.

An important consideration in the approach to recovery from pediatric head injury lies in neither the acute nor chronic responses to the injury itself, but rather, in how the acute dysfunction at a critical developmental window may result in impaired plasticity and altered long-term outcome. One method of measuring developmental plasticity is to track axonal regrowth after a focal brain lesion. Another method is to evaluate how the young brain responds to changes in environmental stimulation, as it is well known that rearing in an enriched environment results in anatomical, molecular and cognitive enhancements ${ }^{60-67}$. While both have been studied in the experimental setting, it is clear that these results have clinical implications.

Normal recovery from a focal brain lesion may require repair of the lesion site itself, recovery of functional connections from the injury site to associated brain regions, and, often, rearrangement of alternate circuitry to allow uninjured regions to compensate for loss of function at the lesion site. In rats, lesions to the entorhinal cortex result in a well-characterized regrowth of axons into the hippocampus, with a circumscribed pattern of synaptic recovery over time. However, the process of axonal regrowth may be disturbed by superimposition of a TBI, suggesting that biomechanical injury can interfere with normal circuit development ${ }^{49}$. From a clinical standpoint, abnormal maturation of neuronal connections is associated with neurological conditions such as epilepsy, developmental delay and even cerebral dysgenesis. Pediatric TBI, perhaps due in part to interference with normal brain development and connectivity, has been associated with subsequent epilepsy, cognitive difficulties, behavioral changes and, in rare cases following very early TBI, cortical dysplasia ${ }^{68,69}$.

Experience-dependent plasticity refers to the phenomenon of how life experiences can mold and shape brain anatomy, connectivity and subsequent function. This plasticity is most robust in the immature brain, and, in children, has been associated with developmental windows for language development, musical talent, acquisition of foreign languages, and many other important functions. Organized education relies on this experience-dependent plasticity by providing specific stimulation to the developing brain with the ultimate goal of enhancing longterm cognitive and behavioral outcomes. In the laboratory, rearing animals in an 'enriched environment' (EE) has been shown to result in increases in cortical thickness, dendritic arborization, number of synapses, neurotransmitter receptors and cognitive functions. The effects of this EE rearing are more robust when it is instituted at an early age.

In contrast to EE rearing following adult TBI, EE rearing immediately following developmental TBI appears to have limited beneficial effects. In fact, rat pups reared in EE beginning 1 day post-TBI appear indistinguishable from those reared in standard (relatively unstimulating) conditions. However, sham pups clearly benefit from EE rearing, showing increased cortical thickness ${ }^{9}$, more elaborate dendritic branching ${ }^{70}$ and improved cognitive performance ${ }^{9,10}$ when compared to their standard-housed peers. This work strongly supports the hypothesis that early TBI can result in abnormal brain responsiveness that ultimately affects cognitive outcome later in life.

Thus, in both animal and human studies, aberrations of the glutamatergic neurotransmitter systems have been reported following TBI $\mathrm{T}^{50,51,71,72}$. Activation of glutamate receptors is a fundamental part of normal cerebral maturation. In fact, rearing in EE has been shown to augment expression of glutamate receptors in uninjured animals. The clinical implications of this work include both the possibility of using measurements of post-TBI brain glutamate/glutamine as a biomarker for injury severity as well as a prognostic indicator of eventual cognitive recovery (or impairment). This also opens the intriguing possibility 
of pharmacological interventions to manipulate these systems in an age and time-after-injury specific fashion to perhaps facilitate optimal recovery.

A final consideration with regards to environmental stimulation is the timing of such stimulation following TBI. Clinical studies clearly show the benefit of a more enriching socioeconomic environment in the recovery after pediatric $\mathrm{TBI}^{73,74}$. At first glance, this appears inconsistent with the animal data that suggests EE is ineffective following developmental TBI. However, by altering the initiation of EE rearing from one day post-injury (where the effects of EE appeared to be minimal) to two weeks post-injury, many of the cognitive enhancements of EE appeared to once again be detectable ${ }^{10}$. Other studies of brain activation in adults also support the idea of a period of reduced neural responsiveness following TBI, both in experimental animals $\mathrm{s}^{53,54,75,76}$ and in human patients ${ }^{77,78}$. In fact, in models of ischemic or lesional brain injury, early neural activation has been associated with worsening of functional outcomes $^{79-81}$, a complication that is avoided by delaying the onset of brain activation. Clinically, this may also be extremely relevant for three reasons. First, the timing of post-injury stimulation may be targeted for a window that will optimize recovery for an individual patient. Second, excessive stimulation too soon after an injury may actually be detrimental. Third, on a societal level, it is important to utilize scarce rehabilitative resources at a time point when they are more likely to do good for a larger number of individuals.

\section{CONCLUSIONS}

In summary, pediatric TBI is a major medical and socioeconomic concern worldwide, and accounts for a disproportionate amount of mortality and morbidity in the younger age groups. Unfortunately, our management of these patients rarely takes into account their unique developmental circumstances and often ignores important distinctions of head injury in children. Some of these distinctions include altered biomechanics, different mechanisms of injury, ongoing myelination of white matter tracts, and maturation of excitatory neurotransmitter circuitry. In particular, developmental changes in excitatory neurotransmission may render the young brain more susceptible to excitotoxic injury, yet, like a two-edged sword, also make the developing brain more sensitive to reductions in stimulation, resulting in altered plasticity or even apoptotic cell death. Experimental investigations into specific developmental aspects of TBI hold promise to improve clinical management of head-injured children by increasing our understanding of the underlying mechanisms of developmental brain injury. This increased knowledge may lead to identification of biomarkers after pediatric TBI, allowing for better determination of injury severity and prognostication of outcome. Furthermore, pharmacological interventions may be targeted to these specific mechanisms, and the effects of such interventions can be followed physiologically as well as with long-term neurocognitive testing. Lastly, given limited access to resources, clearly delineating the optimal timing of rehabilitative efforts will help prevent secondary injury and promote maximal functional recovery in head-injured children.

\section{REFERENCES}

1. Zwienenberg M, Muizelaar JP Severe pediatric head injury: the role of hyperemia revisited.

J Neurotrauma 1999; 16: 937-43.

2. Suzuki K. The changes in regional cerebral blood flow with advancing age in normal children. Nagoya Med J 1990; 34, 159-70.

3. Chugani HT, Phelps ME, MazziottaJC. Positron emission tomography study of human brain functional development. Ann Neurol 1987; 22: 487-97.

4. Friedman WJ, Olson L, Persson H. Cells that Express BrainDerived Neurotrophic Factor mRNA in the Developing Postnatal Rat Brain.

Eur J Neurosci 1991; 3: 688-97.

5. Insel TR, Miller LP, Gelhard RE. The ontogeny of excitatory amino acid receptors in rat forebrain-I. N- methyl-Daspartate and quisqualate receptors. Neuroscience 1990; 35: 31-43.

6. Miller LP, Johnson AE, Gelhard RE, Insel TR. The ontogeny of excitatory amino acid receptors in the rat forebrain-II. Kainic acid receptors. Neuroscience 1990; 35: 45-51.

7. Annegers JF, Grabow JD, Groover RV, Laws ER Jr, Elveback LR, Kurland LT. Seizures after head trauma: a population study. Neurology 1980; 30:683-9..

8. Ikonomidou C, Mosinger JL, Salles KS, Labruyere J, Olney JW. Sensitivity of the developing rat brain to hypobaric/ ischemic damage parallels sensitivity to $\mathrm{N}$-methyl-aspartate neurotoxicity.

J Neurosci 1989; 9: 2809-18.

9. Fineman I, Giza CC, Nahed BV, Lee SM, Hovda DA. Inhibition of neocortical plasticity during development by a moderate concussive brain injury.

J Neurotrauma 2000; 17: 739-49.

10. Giza CC, Griesbach GS, Hovda DA. Experience-dependent behavioral plasticity is disturbed following traumatic injury to the immature brain.

Behav Brain Res 2005; 157: 11-22.

11. Bittigau $\mathrm{P}$, Sifringer $\mathrm{M}$, Pohl D, et al. Apoptotic neurodegeneration following trauma is markedly enhanced in the immature brain. Ann Neurol 1999; 45: 724-35

12. Pohl D, Bittigau P, Ishimaru MJ, et al. N-Methyl-D-aspartate 
antagonists and apoptotic cell death triggered by head trauma in developing rat brain.

Proc Natl Acad Sci U S A 1999; 96: 2508-13.

13. Katayama Y, Becker DP, Tamura T, Hovda DA. Massive increases in extracellular potassium and the indiscriminate release of glutamate following concussive brain injury. J Neurosurg 1990; 73: 889-900.

14. Yoshino A, Hovda DA, Kawamata T, Katayama Y, Becker DP. Dynamic changes in local cerebral glucose utilization following cerebral conclusion in rats: evidence of a hyper- and subsequent hypometabolic state.

Brain Res 1991; 561: 106-19.

15. Hovda DA. In, Narayan RK, WilbergerJE, Povlishock JT (eds). Neurotrauma. (McGraw-Hill, San Francisco,1996); pp. 1459-78.

16. Thomas S, Prins ML, Samii M, Hovda DA. Cerebral metabolic response to traumatic brain injury sustained early in development: a 2-deoxy-D-glucose autoradiographic study. J Neurotrauma 2000; 17: 649-65.

17. Prins ML, Hovda DA. Traumatic brain injury in the developing rat: effects of maturation on Morris water maze acquisition. J Neurotrauma 1998; 15: 799-811.

18. Prins ML, Hovda DA. Mapping cerebral glucose metabolism during spatial learning: interactions of development and traumatic brain injury.

J Neurotrauma 2001; 18: 31-46.

19. Osteen CL, Moore AH, Prins ML, Hovda DA. Age-dependency of 45 calcium accumulation following lateral fluid percussion: acute and delayed patterns.

J Neurotrauma 2001; 18: 141-62.

20. Prins ML, Lee SM, Cheng CL, Becker DP, Hovda DA. Fluid percussion brain injury in the developing and adult rat: a comparative study of mortality, morphology, intracranial pressure and mean arterial blood pressure. Brain Res Dev Brain Res 1996; 95: 272-82.

21. Gurkoff G, Hoffmann JR, Giza CC, Hovda DA. Injury severity does not predict outcome in a model of developmental lateral fluid percussion.

J Neurotrauma 2003; 20: 2003. (Abstract).

22. Adelson PD, Jenkins LW, Hamilton RL, Robichaud P, Tran MP, Kochanek PM.. Histopathologic response of the immature rat to diffuse traumatic brain injury. J Neurotrauma 2001; 18: 967-76.

23. Conti AC, Raghupathi R, Trojanowski JQ, McIntosh TK. Experimental brain injury induces regionally distinct apoptosis during the acute and delayed post-traumatic period.

J Neurosci 1998; 18: 5663-672.

24. Tong W, Igarashi T, Ferriero DM, Noble LJ. Traumatic brain injury in the immature mouse brain: characterization of regional vulnerability.

Exp Neurol 2002; 176:105-16.

25. Prins ML, Hovda DA. Developing experimental models to address traumatic brain injury in children. J Neurotrauma 2003; 20:123-37.

26. Ikonomidou C, Qin Y, Labruyere J, Kirby C, Olney JW. Prevention of trauma-induced neurodegeneration in infant rat brain

Pediatr Res 1996; 39: 1020-7.

27. Ikonomidou C, Turski L. Why did NMDA receptor antagonists fail clinical trials for stroke and traumatic brain injury? Lancet Neurol 2002; 1: 383-86.

28. Bigler ED, Johnson SC, Blatter DD. Head trauma and intellectual status: relation to quantitative magnetic resonance imaging findings.

Appl Neuropsychol 1999; 6: 217-25.

29. Verger K, Junque C, Levin HS, et al. Correlation of atrophy measures on MRI with neuropsychological sequelae in children and adolescents with traumatic brain injury. Brain Inj 2001; 15: 211-21.

30. Levin HS, Benavidez DA, Verger-Maestre K, et al. Reduction of corpus callosum growth after severe traumatic brain injury in children.

Neurology 2000; 54: 647-53.

31. Wilde EA, et al. Frontal and temporal morphometric findings on MRI in children after moderate to severe traumatic brain injury.

J Neurotrauma 2005; 22: 333-44.

32. Adelson PD, Dixon CE, Robichaud P, Kochanek PM. Motor and cognitive functional deficits following diffuse traumatic brain injury in the immature rat. J Neurotrauma 1997; 14: 99-108.

33. Adelson PD, Dixon CE, Kochanek PM. Long-term dysfunction following diffuse traumatic brain injury in the immature rat. J Neurotrauma 2000; 17: 273-82.

34. DeFord SM, Wilson MS, Rice AC, et al. Repeated mild brain injuries result in cognitive impairment in $\mathrm{B} 6 \mathrm{C} 3 \mathrm{~F} 1$ mice. J Neurotrauma 2002; 19: 427-38.

35. Collins MW, Lovell MR, Iverson GL, Cantu RC, Maroon JC, Field M. Cumulative Effects of Concussion in High School Athletes. Neurosurgery 2002; 51: 1175-81.

36. Collins MW, Grindel SH, Lovell MR, et al. Relationship between concussion and neuropsychological performance in college football players.

JAMA 1999; 282: 964-70.

37. Field M, Collins MW, Lovell MR, Maroon J. Does age play a role in recovery from sports-related concussion? A comparison of high school and collegiate athletes. $J$ Pediat 2003; 142: 546-53.

38. Matser EJ, Kessels AG, Lezak MD, Jordan BD, Troost J. Neuropsychological impairment in amateur soccer players. JAMA 1999; 282: 971-3.

39. Ewing-Cobbs L, Fletcher JM, Levin HS, Iovino I, Miner ME. Academic achievement and academic placement following traumatic brain injury in children and adolescents: a two-year longitudinal study. J Clin Exp Neuropsychol 1998; 20: 769-81.

40. Levin HS, Eisenberg HM, Wigg NR, Kobayashi K. Memory and intellectual ability after head injury in children and adolescents.

Neurosurgery 1982; 11:668-73.

41. Taylor HG, Alden J. Age-related differences in outcomes 
following childhood brain insults: an introduction and overview. J Int Neuropsychol Soc 1997; 3: 555-67.

42. Ewing-Cobbs L, Prasad MR, Landry SH, Kramer L, DeLeon R. Executive functions following traumatic brain injury in young children: a preliminary analysis.

Dev Neuropsychol 2004; 26: 487-512.

43. Jaffe KM, Polissar NL, Fay GC, Liao S. Recovery trends over three years following pediatric traumatic brain injury. Arch Phys Med Rehabil 1995; 76: 17-26.

44. Levin HS, Hanten G, Chang CC, et al. Working memory after traumatic brain injury in children. Ann Neurol 2002; 52: 82-8.

45. Yeates KO, Taylor HG, Wade SL, Drotar D, Stancin T, Minich N. A prospective study of short- and long-term neuropsychological outcomes after traumatic brain injury in children.

Neuropsychology 2002; 16: 514-23.

46. Giza CC, Li HH, Prins ML, Hovda DA. Gene expression profiling after lateral fluid percussion injury in the immature rat suggests multiple mechanisms of neural dysfunction. J Neurotrauma 2003; 20: 1101.(Abstract).

47. Giza CC, Cai Y, Prins ML, Hovda DA. Lateral fluid percussion injury in the developing rat triggers expression changes in multiple families of cell cycle, developmental and cytoskeletal genes.

Restorative Neurol and Neurosci 2004; 23(3,4): 209. 10 (Abstract).

48. Griesbach GS, Hovda DA, Molteni R, Gomez-Pinilla F Alterations in BDNF and synapsin I within the occipital cortex and hippocampus after mild traumatic brain injury in the developing rat: reflections of injury-induced neuroplasticity. $J$ Neurotrauma 2002; 19: 803-14.

49. Prins ML, Povlishock JT, Phillips LL. The effects of combined fluid percussion traumatic brain injury and unilateral entorhinal deafferentation on the juvenile rat brain.

Brain Res Dev Brain Res 2003; 140: 93-104.

50. Giza CC, Santamaria NS, Hovda DA. N-methyl-D-aspartate receptor subunit changes following traumatic injury to the developing brain.

J Neurotrauma, in press 2006.

51. Santamaria NS, Hovda DA, Giza CC. Alteration in N-methylD-aspartate subunit composition and impaired neuroplasticity after fluid percussion injury in the developing rat. J Neurotrauma 2004; 21: 1329. (Abstract).

52. D'Ambrosio R, Maris DO, Grady MS, Winn HR, Janigro D. Selective loss of hippocampal long-term potentiation, but not depression, following fluid percussion injury. Brain Res 1998; 786: 64-79.

53. Dietrich WD, Alonso O, Busto R, Ginsberg MD. Widespread metabolic depression and reduced somatosensory circuit activation following traumatic brain injury in rats. J Neurotrauma 1994; 11: 629-40.

54. Sick TJ, Perez-Pinzon MA, Feng ZZ. Impaired expression of long-term potentiation in hippocampal slices 4 and $48 \mathrm{~h}$ following mild fluid-percussion brain injury in vivo. Brain Res 1998; 785: 287-92.

55. Osteen CL, Giza CC, Hovda DA. Injury-induced alterations in
$\mathrm{N}$-methyl-D-aspartate receptor subunit composition contribute to prolonged (45)calcium accumulation following lateral fluid percussion.

Neuroscience 2004; 128: 305-22.

56. Biegon A, Fry PA, Paden CM, Alexandrovich A, Tsenter J, Shohami E. Dynamic changes in N-methyl-D-aspartate receptors after closed head injury in mice: Implications for treatment of neurological and cognitive deficits. Proc Natl Acad Sci U S A 2004; 101: 5117-22.

57. Raghupathi R, Mehr MF, Helfaer MA, Margulies SS. Traumatic axonal injury is exacerbated following repetitive closed head injury in the neonatal pig. J Neurotrauma 2004; 21: 307-16.

58. Tong KA, Ashwal S, Holshouser BA, et al. Hemorrhagic shearing lesions in children and adolescents with posttraumatic diffuse axonal injury: improved detection and initial results. Radiology 2003; 227, 332-9.

59. Tong KA, Ashwal S, Holshouser BA, et al. Diffuse axonal injury in children: clinical correlation with hemorrhagic lesions. Ann Neurol 2004; 56: 36-50.

60. Bennett EL, Diamond MC, Krech D, Rosenzweig MR. Chemical and anatomical plasticity of brain. Science 1964; 164: 610-19.

61. Diamond MC, Krech D, Rosenzweig MR. The effects of an enriched environment on the histology of the rat cerebral cortex.

J Comp Neurol 1964; 123: 111-20.

62. Greenough WT, Volkmar FR, Juraska JM. Effects of rearing complexity on dendritic branching in frontolateral and temporal cortex of the rat. Exp Neurol 1973; 41: 371-8.

63. Rampon $\mathrm{C}$, Jiang $\mathrm{CH}$, Dong $\mathrm{H}$, et al. Effects of environmental enrichment on gene expression in the brain. Proc Natl Acad Sci U S A 2000; 97: 12880-4.

64. Rosenzweig MR, Bennett EL. Psychobiology of plasticity: effects of training and experience on brain and behavior. Behav Brain Res 1996; 78:57-65.

65. Tang YP, Wang H, Feng R, Kyin M, Tsien JZ. Differential effects of enrichment on learning and memory function in NR2B transgenic mice. Neuropharmacology 2001; 41: 779-90.

66. Tees RC, Buhrmann K, Hanley J. The effect of early experience on water maze spatial learning and memory in rats. Dev Psychobiol 1990; 23: 427-39.

67. Venable N, Pinto-Hamuy T, Arraztoa JA, et al. Greater efficacy of preweaning than postweaning environmental enrichment on maze learning in adult rats.

Behav Brain Res 1988; 31: 89-92.

68. Marin-Padilla M, Parisi JE, Armstrong DL, Sargent SK, Kaplan JA. Shaken infant syndrome: developmental neuropathology, progressive cortical dysplasia, and epilepsy. Acta Neuropathol (Berl) 2002: 103: 321-32.

69. Lombroso CT. Can early postnatal closed head injury induce cortical dysplasia. Epilepsia 2000; 41: 245-53.

70. Ip EY, Giza CC, Griesbach GS, Hovda DA. Effects of enriched 
environment and fluid percussion injury on dendritic arborization within the cerebral cortex of the developing rat. J Neurotrauma 2002; 19: 573-85.

71. Miller LP, Lyeth BG, Jenkins LW, et al. Excitatory amino acid receptor subtype binding following traumatic brain injury. Brain Res 1990; 526: 103-7.

72. Ashwal S, Holshouser B, Tong K, et al. Proton MR spectroscopy detected glutamate/glutamine is increased in children with traumatic brain injury.

J Neurotrauma 2004; 21: 1539-52.

73. Hawley CA, Ward AB, Magnay AR, Long J. Outcomes following childhood head injury: a population study.

J Neurol Neurosurg Psychiat 2004; 75: 737-42.

74. Taylor HG, et al. A prospective study of short- and long-term outcomes after traumatic brain injury in children: behavior and achievement.

Neuropsychology 2002;16: 15-27.

75. Griesbach GS, Hovda DA, Molteni R, Wu A, Gomez-Pinilla F. Voluntary exercise following traumatic brain injury: brainderived neurotrophic factor upregulation and recovery of function.

Neuroscience 2004; 125:129-139.
76. Ip EY, Zanier ER, Moore AH, Lee SM, Hovda DA. Metabolic, neurochemical, and histologic responses to vibrissa motor cortex stimulation after traumatic brain injury.

J Cereb Blood Flow Metab 2003; 23: 900-10.

77. Jantzen KJ, Anderson B, Steinberg FL, Kelso JA. A prospective functional MR imaging study of mild traumatic brain injury in college football players. AJNR 2004; 25: 738-45.

78. McAllister TW, Saykin AJ, Flashman LA, et al. Brain activation during working memory 1 month after mild traumatic brain injury: a functional MRI study. Neurology 1999; 53: 1300-8.

79. Humm JL, Kozlowski DA, Bland ST, James DC, Schallert T. Use-dependent exaggeration of brain injury: is glutamate involved?

Exp Neurol 1999; 157: 349-58.

80. Kozlowski DA, James DC, Schallert T. Use-dependent exaggeration of neuronal injury after unilateral sensorimotor cortex lesions.

J Neurosci 1996; 16: 4776-86.

81. Leasure JL, Schallert T. Consequences of forced disuse of the impaired forelimb after unilateral cortical injury. Behav Brain Res 2004; 150: 83-91. 